\title{
EL ECLIPSE DEL TRABAJO Y LOS RIESGOS PARA LA DEMOCRACIA Y LA CONSTITUCIÓN REPUBLICANA *
}

\author{
Dino Greco \\ Director del periódico Liberazione
}

RESUMEN. Este trabajo es una defensa, desde la perspectiva de un sindicalista, del constitucionalismo de signo ferrajoliano en relación con los derechos sociales en general y los derechos de los trabajadores en particular, frente al proceso de precarización laboral y de disolución y mercantilización del Derecho del trabajo experimentado en países como Italia en las últimas décadas. El autor defiende la constitucionalización de los derechos laborales como límite sustancial de lo decidible por mayoría (tanto frente a una mayoría sindical como frente al legislador); la universalidad y exigibilidad de esos derechos (que no serían de rango inferior); e incluso la dependencia de la efectividad de los derechos de libertad respecto de los derechos sociales. Sin embargo, pese a la constitucionalización formal de los derechos sociolaborales, su sustancia y efectividad estarían siendo vulneradas por el actual dominio del mercado, la privatización de servicios públicos, la subasta a la baja en las condiciones laborales, la vuelta a la contratación laboral individual recortando la negociación colectiva, el dominio del PIB como parámetro del bienestar social, etc., habiéndose producido además una formalización jurídica de esa precariedad laboral (pérdida de la función originaria del Derecho del trabajo, que se reasimila al Derecho mercantil) y la racionalización ideológica de ese proceso de dominio del mercado. La solución a esta situación no es menos sino más (más intensa y más efectiva) constitucionalización de los derechos sociales, en la dirección de una «democracia social como ensanchamiento del Estado de derecho».

Palabras clave: FerRAJoli, derechos sociales, Derecho del trabajo, Estado social, constitucionalismo, mercado.

ABSTRACT. This paper is a defence, from the point of view of a trade unionist, of Ferrajolian constitutionalism regarding social rights in general and, specifically, workers' rights, against the background of the current process of the undermining of such rights and the weakening and commercialization of labour law in countries such as Italy. The author advocates the constitutionalization of labour rights as substantive limits on majoritarian decisions (against both trade union majorities and the legislature); the universality and enforceability of such rights (which are not second-rate rights); and even the dependence of the effectiveness of liberty rights on social rights. However, despite the formal constitutionalization of socio-labour rights, their substance and effectiveness are being violated by the current power of free-market economy, the privatization of public services, the worsening of work conditions, the return to individual contracting against collective bargaining, the dominance of GDP as the main parameter for social welfare, and so on. We are also witnessing a legal formalization of the mentioned undermining of workers' conditions (withering away of the original role of labour law, which is being assimilated to commercial law), as well as an ideological rationalization of that process of market dominance. The solution to this situation is not less but more - more intense and more effective - constitutionalization of social rights, in the direction towards a «social democracy as an enlargement of the rule of law». market.

Keywords: FERRAJOLI, social rights, Labour Law, Welfare State, constitutionalism,

\footnotetext{
* Fecha de recepción: 1 de diciembre de 2008. Fecha de aceptación: 18 de diciembre de 2008.
} 


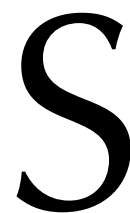

e preguntarán - y, francamente, me lo he preguntado también yo- qué hace un sindicalista en una reunión de estudiosos y académicos del Derecho tan prestigiosos. Mi presencia se debe al coraje de T. MAZZARESE al enviarme su invitación y a mi temeridad al aceptarla. Espero no lamenten mi osadía.

Va de suyo que mi contribución será inevitablemente excéntrica y quizás un tanto naïf en relación con las demás intervenciones, pues se origina en un punto de observación diferente. Espero, sin embargo, que no sea totalmente ajena al análisis, que hoy tiene lugar, del extraordinario (una de las pocas veces en que es apropiado utilizar este adjetivo) trabajo de L. FERRAJOLI.

Quisiera organizar mi razonamiento alrededor de tres ejes centrales o, mejor dicho, de tres tesis que se conectan entre ellas.

La primera: la constitucionalización de los derechos y la insustituibilidad democrática de una esfera de lo indecidible, de lo indisponible, esto es, de los límites de la soberanía popular que no puede (no debe) nunca transformarse en «dictadura de la mayoría». Y esto, para decirlo con FERRAJOLI, porque la democracia no puede reducirse a un hecho puramente procedimental, limitándose a establecer «quién decide» y «cómo decide» y desinteresándose de «qué cosa se decide». La democracia no puede se indiferente hacia el contenido de la decisión.

La segunda: la efectividad de los derechos de libertad depende, como una condicio sine qua non, de la garantía de los derechos sociales. Ello queda demostrado por el hecho de que el desarrollo de la democracia (y, en contra de lo que el pensamiento liberal sostiene, de la economía misma) ha sido posible sólo en aquellos países que lograron resolver los problemas vitales mínimos, asegurando a todos asistencia, salud, educación. Sin esa garantía los derechos de libertad, de hecho, se debilitan e, inexorablemente, se extinguen.

La tercera: los derechos sociales no son (no deben ser) derechos de segundo grado, de rango inferior, faltos de exigibilidad y consecuentemente débiles, meras expresiones de ideales. Mucho menos pueden encontrarse subordinados a otras exigencias que han sido indebidamente elevadas a paradigmas constitucionales.

Como es evidente no se trata de una hipótesis abstracta. El mercado y la libre competencia empresarial se han transformado en el dominus indiscutido de los tiempos modernos. La globalización se encuentra fundada sobre la primacía de organismos del todo faltos de legitimación democrática (la Organización Mundial de Comercio, el Fondo Monetario Internacional, el Banco Mundial).

La Europa Unida, sin Constitución, es la Europa de la moneda, la Europa del Tratado de Maastricht. El gobierno italiano, que en cambio posee una Constitución en la cual inspirarse, sanciona sin ningún problema una ley de presupuestos en la que se privilegia la cancelación de la deuda pública frente a las jubilaciones, la protección de la renta especulativa frente a los problemas de autosuficiencia de los ancianos, las transferencias a las empresas frente al salario mínimo vital y el sistema de protección social. Es por esto que no es ocioso preguntarse: ¿cuál es el origen constitucional de estas elecciones? 
En cuanto a la primera tesis, se ha dicho que el poder soberano no es ilimitado, pues «la mayoría no puede disponer de aquello que no le pertenece por ser de todos y de cada uno». Si no fuera así sería posible, por mayoría, suprimir incluso la libertad. Tal como ha sido el caso en la Italia de 1925 y en la Alemania de 1933. Existen por tanto límites infranqueables, cuyo sentido fuerte se encuentra resumido en la Constitución francesa, de factura rousseauniana, de 1793: «Existe opresión contra cada miembro cuando el cuerpo social es oprimido».

Este principio sacrosanto vale (debería valer) también en el mundo del trabajo, especialmente en materia sindical, donde, a decir verdad, la democracia se encuentra bastante asediada. Aun cuando en el ámbito laboral sean necesarias reglas claras que, en contra del intento de apropiación por parte de la burocracia, establezcan la soberanía de los trabajadores sobre todo acto negocial a ellos referido, debe subrayarse que necesariamente ese poder tiene límites. Por ejemplo, frente a una crisis empresarial, no puede permitirse a la mayoría de los trabajadores que decida si, para salvarse ella misma, acepta o no el despido de una porción minoritaria de trabajadores. Y esto porque el derecho al trabajo es un derecho individual no disponible.

Todo ello — dicho sea de paso- aun sin mencionar que, si eso ocurre, se desintegra instantáneamente la idea misma de sindicato fundada sobre la solidaridad. Una vez debilitada la solidaridad se disuelve toda asociación que se funde sobre un pacto de igualdad, de apoyo mutuo y de reciprocidad, y en la que cada miembro es el tercero controlador del otro.

Numerosos ejemplos proporcionan la prueba de que los derechos fundamentales o bien son universales (y universalmente exigibles) o bien no son; propongo dos. Primero: la limitación legislativa del ámbito de aplicación del estatuto de los derechos de los trabajadores, o al menos de su núcleo central $(v . g$., el derecho a no ser despedido sin justa causa o motivo justificado), mediante su reducción a los sectores empresariales con más de 15 dependientes, con el tiempo ha generado, incluso dentro de la franja protegida, un progresivo proceso de erosión de esos derechos.

$\mathrm{El}$ aguerrido ataque que un gran número de juristas laboralistas ha dirigido contra los beneficiarios de la Ley 300 de 1970, señalándolos como los privilegiados (insiders) que impiden a los demás (outsiders) el acceso a ciertos derechos y al trabajo, demuestra cómo los derechos que no se extienden a todos resultan inevitablemente degradados. Y finalmente la muralla que pretendía protegerlos, no logrando resistir el asedio, resulta expugnada.

El segundo ejemplo se refiere al hecho de que existe actualmente en Italia un Derecho dual, ya que para tres millones y medio de personas, inmigradas a nuestro país, rige un estatuto especial. Un estatuto especial referido al sufragio, el trabajo, la subsistencia, la salud, etc., y sin contar que una porción enorme de ellos experimenta una reducción a la esclavitud.

Ahora bien, no es fortuito que formas de trabajo cada vez más serviles encuentren un lugar también entre los nativos, pues cuando en un dique se ha formado una grieta, es previsible que este termine por romperse.

En cuanto a las tesis segunda y tercera, debe decirse que hoy los principios constitucionales han sido tergiversados exactamente en el punto crucial de la relación 
entre capital y trabajo. Punto que no creo represente un aspecto marginal en nuestra Carta.

Es mi opinión que la reciente victoria en el referéndum sobre las reformas constitucionales queridas por el centroderecha ha logrado defender sólo el mito de la Constitución, pero no su sustancia, mucho más profunda e insistentemente vulnerada. Es por ello que, aun siendo importante, el resultado de esa prueba no ha logrado interrumpir una larga trayectoria de quebrantamientos de la Constitución.

Tomemos, por ejemplo, el art. 41 del Título III de la Constitución, a cuya formulación contribuyó de manera fundamental, no casualmente, G. DI VITTORIO. El artículo dice, textualmente: «La iniciativa económica privada es libre. No podrá, sin embargo, desarrollarse (nótese el carácter imperativo de la fórmula) en contra del interés social o de tal modo que inflija un perjuicio a la seguridad, a la libertad y a la dignidad humana». Tal es así que (tercer inciso) «La ley determinará los programas y controles oportunos para que la actividad económica pública y privada puedan ser coordinadas y encaminadas a fines sociales». En otros términos, los fines sociales y los derechos de los trabajadores se encuentran sobreordenados respecto al beneficio empresarial. Por lo que, donde aquellos se encuentren en discusión, el Estado debe intervenir para preservar su exigibilidad. Con los arts. 42 y 43 la Constitución entra explícitamente en los derechos de propiedad y condiciona su ejercicio, llegando a prever, bajo determinadas condiciones, la expropiación.

Ahora bien, puede decirse, sin ninguna exageración, que la realidad ha, literalmente, tergiversado el orden de los valores. En virtud de ello podríamos releer la constitución material de las relaciones sociales en el modo siguiente: «la seguridad, la libertad, la dignidad humana deben ser garantizadas siempre y cuando no entren en conflicto con la actividad económica libre, con los intereses privados, con la recuperación del capital invertido, con la competitividad de la empresa, etc.».

En conclusión, el mercado se comporta como primus, como sociedad natural y como criterio ordenador incluso en otras esferas de la actividad pública.

Piénsese en la privatización o empresarialización de los servicios públicos. También aquí, el fin y la utilidad social ya no son la garantía de un derecho protegido constitucionalmente. Por lo tanto asiste la razón a FERRAJOLI cuando advierte que nos encontramos frente a un clamoroso conflicto de intereses, en virtud del cual es necesario afirmar que «son públicas y deben sustraerse a la lógica del mercado todas las funciones y actividades que, aun cuando gestionadas por privados, son de interés público y/o destinadas a la tutela o a la satisfacción de derechos fundamentales».

La opinión opuesta se encuentra, en cambio, bastante extendida. Su extensión se revela en el hecho de que los derechos han sido, en el debate político, degradados al rango de costos y las instituciones al rango de sociedades comerciales con fines de lucro. ¿Un ejemplo? Téngase en mente la regla de la oferta más baja, criterio basilar en las licitaciones públicas. ¿Cuáles son las voces sobre las que se reducen los costos, es decir, sobre las que se ahorra? La seguridad de los trabajadores, sus derechos, su salario, el estándar de los servicios proporcionados, la calidad de las materias entregadas, etc.

Aún más. El iuslaborismo, en su expresión más avanzada, coherentemente con el espíritu y con la letra de la Constitución, ha intentado orientar la ley a favor del más dé- 
bil y en contra de la prepotencia del más fuerte. Este intento tiene en cuenta la evidente asimetría de poder y fuerza que existe entre capital y trabajo, ya que, para ilustrarlo al modo de los clásicos, patrón y obrero podrán ser iguales en lo empírico, pero no en las relaciones sociales; en estas últimas domina quien tiene el poder económico. Por esto la ley debe proteger al más débil, y lo debe proteger también frente a su propia debilidad. Debilidad que podría inducirlo a la renuncia de derechos sustanciales. A ello se debe la indisponibilidad de la norma que instituye un tercero, el Estado, como garante de derechos irrenunciables. Por ello - tal como sostiene gran parte del iuslaborismo contemporáneo - resultan inadmisibles las presiones de Confindustria ${ }^{1}$ para que sea introducida la posibilidad de derogaciones empresariales in pejus de convenios colectivos nacionales. Posibilidad que se desea introducir en los casos en que sea necesario hacer frente a situaciones de crisis o, incluso, en que sólo sea necesario incrementar la competitividad de la empresa.

En qué punto nos encontramos queda documentado por el modelo que una conocida multinacional de electrodomésticos, la Electrolux (Zanussi), ha lanzado en Europa. Esta empresa organiza una subasta entre los trabajadores de sus establecimientos dispersos por Europa. Una subasta de la que resultará vencedor quien se encuentre dispuesto a renunciar a la mayor cantidad de derechos adquiridos, permitiendo así a la empresa reducir significativamente los costes laborales, y conquistando de este modo el derecho a la supervivencia.

En definitiva, ¿en qué consiste el proceso de precarización del que se habla con tanta insistencia? En la disolución del Derecho del trabajo. La precarización sirve para debilitar el poder de asociación de los trabajadores, recorriendo un camino bien definido que lleva, progresivamente, de la contratación colectiva a la individual, y que reproduce esa asimetría de poder y esas relaciones de fuerza que el Derecho del trabajo había limitado.

La precarización impide el ejercicio de los derechos, no tanto porque no se encuentren formalmente reconocidos, sino porque no son ya exigibles. Precisamente, estar sometido al chantaje anula «el derecho a tener derechos».

El proceso de formalización jurídica de esta acelerada inmersión en la precariedad dura ya más de veinte años. Incluso un fundamental baluarte democrático, como lo es el art. 18 de la Ley 300 de 1970, ha sido en buena parte vulnerado, como una suerte de «Línea Maginot» del trabajo, a través de la proliferación de una espectacular maraña de tipologías de trabajo caracterizadas —en su ilusoria variedad— por un común estatus de precariedad. En este conjunto es posible encontrar desde la abolición de la norma que prohibía interponer mano de obra (acción que en el pasado se encontraba penada como delito y que actualmente es considerada una actividad lícita y meritoria), hasta la Ley 30 de 2003. Pasando por el paquete Treu y por una constelación de intervenciones legislativas de las que FERRAJOLI, en una precisa nota que todo sindicalista o aspirante a tal debería memorizar, traza el recorrido ${ }^{2}$. Un recorrido que tiende a marcar el pasaje, o mejor, la reasimilación del Derecho del trabajo al Derecho mercantil que regula la transacción de cosas, de mercaderías. En definitiva, en eso es en lo que vemos

\footnotetext{
${ }^{1}$ N. del T.: Confederación General de la Industria Italiana.

${ }^{2}$ L. Ferrajoli, 2007: Principia juris, vol. II, Roma-Bari: Laterza, p. 296, nota 126.
} 
nuevamente transformarse el trabajo humano: el mercado del trabajo como el mercado de la patata.

Este proceso ha tenido después su racionalización ideológica mediante el reconocimiento explícito de la supremacía ordenadora del mercado sobre el conjunto de relaciones sociales, fundada en la indiscutida asunción de una libertad de empresa plena e incondicionada. Competerá luego al Estado, una vez consolidadas las relaciones de producción, amortizar las contradicciones más evidentes a través de medidas de protección social, más o menos eficaces.

Es interesante observar el extraño destino de las tres banderas que identificaban la revolución francesa: una vez arriadas las de igualdad y fraternidad, queda sólo la de libertad, pero como una prerrogativa no de las personas, sino de una entidad impersonal, a saber, el capital.

Hemos constatado cómo el poder económico ha «colonizado» cada una de las instituciones, desbaratando incluso las ideas de sus potenciales antagonistas y reclutando adeptos y catecúmenos en todas las latitudes. Basta pensar en cómo el Producto Interior Bruto, fundado en la medición del crecimiento cuantitativo, ha sido elevado a índice universal de la calidad de todo sistema económico-social. Un índice que, cual inoxidable fetiche, se ha apoderado de toda discusión y ha ingresado, insustituible, en el léxico de los economistas, políticos y sindicalistas. Ello puede observarse en los criterios con los que Unioncamere ${ }^{3}$ estima el nivel anual del bienestar social. Valen como criterio: el ingreso medio per cápita, la productividad del sistema y la facturación global, el volumen del ahorro y el número de ventanillas bancarias, el número de automóviles patentados y la aglomeración de hipermercados (devenidos en templos del consumo de masas).

No entran en cambio, en el cómputo del bienestar, el nivel de educación y de salud, la eficacia de los servicios, la calidad del agua, del aire, del suelo, la extensión del malestar social, de la drogodependencia, de la enfermedad mental, de la marginalidad, el número de accidentes de trabajo ni la respuesta a necesidades sociales fundamentales.

Cada tanto, desde el ámbito liberal, se oye algún resuello crítico. Puede leerse a G. SARTORI en las páginas del Corriere della Sera criticar la ceguera de «San Mercado», «Su Majestad el mercado, para los laicos», que en la deforestación del Amazonas y en el consecuente aumento del efecto invernadero no sabe ver otra cosa más que una oportunidad para incrementar las ventas de aparatos de aire acondicionado. SARTORI concluye su sarcástica invectiva advirtiendo que «no podremos salvarnos a costos de mercado, pero deberemos salvarnos cueste lo que cueste». Se trata evidentemente de puro sentido común, cuya pérdida confiere la medida en que cierta coacción repetitiva (y autodestructiva) parece haber borrado toda capacidad de razonamiento.

Me permito una cita que, si bien no es breve, es interesante: «No podemos medir el espíritu nacional sobre la base del Down Jones, ni los logros del país sobre la base del producto interior bruto. El PIB comprende la contaminación del aire, la publicidad de los cigarrillos, las ambulancias para liberar las autopistas de las carnicerías de fin de semana $[. .$.$] computa las cerraduras especiales para las puertas de nuestras casas$

\footnotetext{
${ }^{3}$ N. del T.: Union Italiana de las Cámaras de Comercio, Industria, Artesanado y Agricultura.
} 
y las prisiones para aquellos que intentan forzarlas [...] incluye programas televisivos que priorizan la violencia para vender productos violentos a los niños [...] crece con la producción de napalm, misiles y ojivas nucleares [...] incluye también las investigaciones para mejorar la diseminación de la peste bubónica [...] aumenta con los equipamientos que la policía utiliza para dispersar manifestaciones y no hace otra cosa más que aumentar cuando se reconstruyen de sus cenizas los bajofondos populares. El PBI no tiene en cuenta la salud de nuestras familias, la calidad de la educación ni la felicidad en los momentos de ocio [...] no incluye la belleza de nuestra poesía, la solidez de los valores familiares, la inteligencia de nuestro debate ni la honestidad de los empleados públicos [...] no tiene en cuenta la justicia de nuestros tribunales, ni la igualdad en nuestras relaciones $[. .$.$] mide todo, excepto aquello que hace que la vida sea digna de$ ser vivida». ¿Saben quién decía esto? No lo dijo S. LATOUCHE el teórico de la depresión, tampoco A. SEn ni nuestros C. Ravaioli y P. A. DACREMA. Lo dijo R. KenNEDy, el cadete de la nueva frontera, en un discurso pronunciado en marzo de 1968 en la universidad de Kansas cuando, usando palabras de G. MARIOTTI, «el PIB había manifestado sólo en parte su naturaleza de hierba infecciosa y altamente contaminante». Y sin embargo, cuarenta años después, no hay nada más consolidado que el PIB.

Es necesario entonces refundar el concepto de crecimiento en términos de crecimiento multiforme de la personalidad humana, pues es esta la enzima vital del progreso y del sano desarrollo de la economía. Es necesario también restablecer el primado de la política, de la buena política, sobre la economía; ahora que sabemos que el mercado - refractario a todo vínculo externo, símbolo del extremismo competitivo que ha estampado sobre sus banderas mors tua vita mea, y traducción comercial del bellum omnium contra omnes - no tiene ninguna capacidad de autorregulación. No se trata de restablecer un primado omnipotente, sino uno fundado sobre lo que FERRAJOLI llama «la constitucionalización de los derechos sociales». La constitucionalización consiste en confirmarlos sustancialmente a través de normas vinculantes de Derecho positivo, no expropiables, en cuanto «el Derecho no tiene la tarea de acompañar aquello que sucede».

La cuestión acerca de cómo los seres humanos, asociados y reunidos en instituciones libres y democráticas, pueden convertirse en dueños de su destino común encuentra una respuesta en la democracia social como ensanchamiento del Estado de derecho. El Estado social de derecho como sistema de garantías positivas. Por tanto - propone FERRAJOLI- constitucionalizar los derechos y definirlos en su irrevocable especificidad: un salario de ciudadanía (ya que el derecho al trabajo es un derecho débil), deberes de equilibro (del gasto público) en materia social (asistencia sanitaria gratuita, escuela pública gratuita por un cierto número de años) y reducción del horario de trabajo.

He escuchado la crítica que J. J. Moreso y — si no he entendido mal-G. PreteROSSI dirigen, desde perspectivas distintas, a L. FERRAJOLI, la crítica de incurrir en una suerte de «hiperlegalismo». La gigantesca construcción de FERRAJOLI correría el riesgo, señalan, de aparecer como un proyecto sin autor. Un proyecto basado únicamente en una norma, autorreferencial y casi metahistórica, que produciría sus efectos por partenogénesis, independientemente de las relaciones sociales y políticas. MORESO cita, en sustento de su tesis, el hecho de que existen muchos más derechos sociales en Suiza, con escasa constitucionalización, de cuantos existen en Perú, provisto de una Constitución aparentemente garantista. 
Yo no creo, sin embargo, que FerRajoli corra un riesgo semejante. Para FerRAJOLI «el Derecho no es nunca natural: depende de cómo lo hagamos. Y por lo tanto depende de cómo lo queramos, de cómo lo pensemos y de cómo lo reivindiquemos». En definitiva: el Derecho no es, ciertamente, impermeable a las relaciones sociales.

El juez G. PALOMBARINI, en el curso del debate sobre la Constitución italiana que algunos años atrás promoviera la Cámara del Trabajo de Brescia, recordaba el efecto detonador que las luchas sociales de finales de los años sesenta y de la primera mitad de los setenta del siglo pasado habían tenido sobre la producción normativa del Parlamento y sobre la cultura jurídica. En ese momento una nueva generación de magistrados cambia la lectura de la Constitución, una lectura que había permanecido latente durante dos décadas. Es un redescubrimiento provocado por la irrupción, en la escena política y social, de la clase obrera.

La constitucionalización de los derechos es siempre importantísima, aun cuando la producción del Derecho no sea nunca neutra y aun cuando el Derecho no se encuentre socialmente desencarnado. Pues permite la consolidación jurídica de las conquistas de la civilización y su incorporación al sentido común, confiriéndoles una fuerza normativa estable.

Cada vez que hemos ignorado este aspecto nos hemos arrepentido, pues si bien es cierto que las relaciones sociales influyen en la producción jurídica, también es cierto lo contrario, a saber, que la afirmación de un Derecho positivo retroactúa sobre las relaciones sociales e influye en su dinámica. Por ejemplo, la posesión del Estatuto de Trabajadores ha permitido que se desarrollara la sindicalización incluso en periodos de retroceso del movimiento.

La otra crítica, probablemente más radical, dirigida a la obra de FERRAJOLI es la que lo acusa de presentarse como un imponente proyecto de reforma social fundado sobre el Derecho, lo cual no es sino fruto de una fe ilustrada en la razón intrínsecamente poco realista.

Sobre esto, he de ser absolutamente sincero, no tengo nada que decir. Pues irrealismo o utopismo son las acusaciones que reiteradamente esgrimen todos los conservadurismos, la estaca que sistemáticamente se clava sobre aquellos proyectos que pretenden cambiar el orden de cosas existente.

En efecto, toda transformación profunda comporta una fatigosa puesta en discusión de la realidad, en este caso de la ausencia de derechos y por lo tanto implica una engelsiana «negación de la negación».

Un viejo partisano, originario de Brescia, protagonista a lo largo de toda su vida de muchísimas batallas contra la corriente y a favor de la libertad y la democracia, solía decir que «el realismo es la virtud de quien tiene la panza llena». Creo que tenía profundamente razón.

(Traducción de Federico Arena) 